\title{
CHARACTERISTICS OF HOMEMADE EXPLOSIVE MATERIALS AND THE POSSIBILITIES OF THEIR IDENTIFICATION
}

\author{
Tibor HORVÁTH \\ National University of Public Service, Budapest, Hungary \\ horvathtibor@uni-nke.hu \\ István EMBER \\ National University of Public Service, Budapest, Hungary \\ ember.istvan@uni-nke.hu
}

\begin{abstract}
One of the greatest challenges for explosive ordnance disposal operators is the disarming process of an improvised explosive device. These dangerous devices are often made from homemade explosive. Committing a bomb attack in urban areas is a basic weapon of terrorists, which may claim civilians' lives. The main aim of experts is to avoid any lethal attack and to stop terrorists who endanger our life. Identifying homemade explosives may also help during the fight against terrorism since information may be provided this way, which is essential for professionals who work in the areas of operations. Usage of high-tech equipment provides stable and reliable background in the field of explosives' analysis.
\end{abstract}

KEYWORDS: explosive material, homemade, terrorism, bomb attack

\section{Introduction}

Among the weapons used by terrorists, improvised explosive devices (IEDs), a.k.a. homemade bombs as nicknamed in common parlance, are perhaps the best-known ones used in bomb attacks. They are well known because their use is widespread even outside the areas of operations, and their targets are not exclusively uniformed personnel. Such attacks claim many civilian casualties and earn enormous media value. Both this latter feature and the tremendous speed of the flow of global news provide grist to the mill of terrorists, as they can instantly instil fear in the hearts of people around the world (Bucsák et al. 2015).
However, this is not all, because the media can create for them that publicity that reaches their potential supporters and thus gain additional financial resources (Resperger, 2018).

Of course, support may also be other than that of a purely material nature (e.g. information, real estate, preparation, transport, production and distribution of propaganda material, etc.) (Vass \& Padányi, 2016). Under such circumstances, the means and methods of terrorism must be managed and eliminated carefully and with maximum efficiency.

These are the causes that make these destructive tools the subject of constant 
analysis and research. The constant attention is not useless considering that it is only the attackers' imagination that sets the limits for the design of explosive devices therefore it is possible to refrain from usual, "stencilled" solutions during the construction and assembly of such devices.

We consider it essential to determine the most important parameters and capabilities of the technical devices necessary for the identification of homemade explosive materials. As a result of these data, we make an attempt to find and present the types that meet the requirements.

In this way, it is likely that it will be possible to identify a tool or several tools that can facilitate the operational work of professionals and increase safety during activities in the area of operations.

\section{Taxonomy of Explosives}

First of all, we consider it important to position homemade explosives in the taxonomy of explosive materials. However, the definition should be started a little farther away. What are explosive materials? It is not very trivial to answer this question because there exist countless domestic and foreign definitions.

We consider the version of this chaotic, yet very similar range of definitions published in the latest Hungarian literature to be authoritative, according to which: "an explosive material is a chemical compound usable in practice which - after an appropriate initial ignition during a chemical reaction (transformation), suddenly (in one hundred thousandths of a second) turns into high-temperature and very high-pressure products, mainly gas, which, during their expansion, carry out extremely high-power work and have an impact on environment" (Lukács, 2017).

These substances can be classified according to the following aspects based on their use:

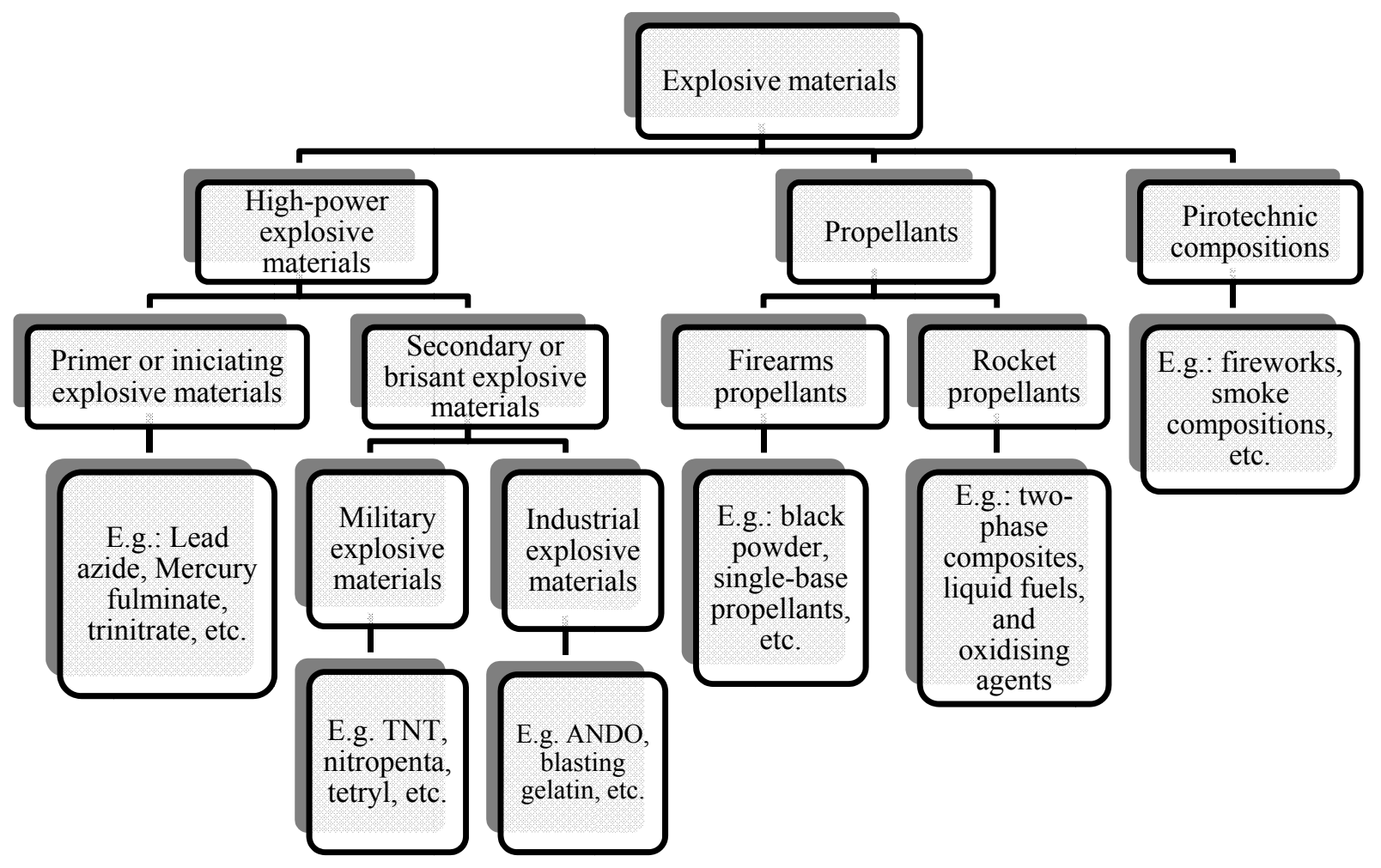

Figure no. 1: Classification of explosive materials based on their use (Source: Lukács, 2017) 
There is another group as well that includes industrially manufactured chemical products made for non-explosive purposes. These substances include ammonium nitrate-based fertilizers, chlorate-containing herbicides, organic peroxides, and polymerized catalysts, nitro-glycerine and nitropenta derivatives, insecticides, and gas generating additives for the plastics industry (Lukács, 2017).

This latter list is especially important for the present paper, as it contains off-theshelf explosive substances or materials with limited explosive characteristics. As in all similar cases, these are the most readily available chemical raw materials for terrorists with criminal intent producing explosive devices. Of course, their effectiveness is incomparable to that of military explosives, for example, therefore their criminal use is also limited.

If taking the use of explosives in a broader sense, the group of "criminally made" explosives is missing from the figure above. In fact, these homemade explosives differ mostly in the method of their preparation and the quality of the final products only. In this case, assassins try to reproduce an industrial product. Of course, there are a few types of explosives that are not very common in industrial production today. One of them is the particularly dangerous, so-called triacetone triperoxide (TATP), which is used and prepared both by terrorists and criminals at home.

\section{Improvised Explosive Devices and Their Possible Charges}

The explicitly destructive means of terror are therefore improvised explosive devices. But how do we define these structures? Zoltán Kovács defines them as follows: "Improvised explosive devices are "homemade" devices, i.e. devices manufactured under non-industrial conditions, which have a destructive effect based on the force of the explosion, chemical, biological substances, pyrotechnic devices, or incendiary effects" (Kovacs, 2012).

These dangerous devices may be either mobile or stationary, and both versions can be planted in a Vehicle-Borne Explosive Device (VBIED). The most important types of improvised explosive devices are as follows:

- Victim-operated IED (VOIED): activated by the target person with the use of a mechanical, electrical, electronic, or combined method. Such a device has the advantage of precise detonation, however, the assassin has no effect on its functioning (it can also be detonated by an innocent person);

- Time Delay IED (TDIED): such a device is mainly usable for attacks on major targets, buildings, or mass events, and provides high security for the attacker, who, on the other hand, is not able to effect its operation after installation;

- Wire command IED: wired (WCIED), Radio-command IED (RCIED), Suicide-borne or Suicide-vehicle Borne (SBIED or SVBIED) versions that require the relative proximity of the assassin or even force them to sacrifice their life, but the destruction can be maximized (Daruka, 2012).

Such devices have three main components:

- an explosive charge, which may also consist of munition(s) of military origin;

- a triggering mechanism;

- a power source, although nonelectrical structures are possible.

Of course, in dependence on the imagination of the maker, any other device and solution may also be incorporated, but from the point of view of deactivation, these three main elements are fundamental. These are the factors that determine the performance of a device because only the connection of these three main parts guarantees an explosion, at least in the case of electrical systems (Horváth, 2019). 
In the present study, we intend to address the explosive charge. This component may be made from explosive materials produced under different industrial conditions, explosives of military materiel or substance illegally extracted from such materiel, or homemade explosives.

The full range of explosive materials produced by industry is suitable for such devices, but of course, some types are more and some others are less well suited for a particular terrorist act. In this respect, military explosive materials would be more suitable, but they are particularly difficult to obtain and, like in the case of industrial types, the supply line can be traced back. In the case of the latter, it is only illegal procurement methods that ensure the maintenance of the cover-up, but this additional crime also increases the possibility of arrest.

The use of explosives military materiel is an obvious solution, but due to its huge metal content such a device is difficult to handle or transport in many cases. It is beyond dispute that the effectiveness of grenades and bombs developed for the destruction of manpower makes them outstanding for civilian targets, but such materiel can only be obtained under limited circumstances. Of course, elements of critical infrastructure can also be targeted. In such a case, it is no longer necessarily effective to carry out an attack with unexploded ordnance. Unexploded ordnance (UXO) may be present in former or active areas of operation and may be suitable for criminal use. It is also possible to extract the explosive material contained in such devices in some way, and to use only that for later bomb attacks.

Such an activity is especially dangerous, and UXO personnel minimize this type of professional task around the world. In Hungary, however, such actions sometimes result in an accident. Recently, for example, there an explosion took place in a condominium, when relics and souvenirs were being made from emptied and "disarmed" grenades. In such a case of non-terrorist passions, however, another important question also arises: where did the explosive go from the "disarmed" devices? This is not merely a criminal issue, because these compounds are known to have serious detrimental effects when released into the environment.

The next solution to produce an explosive charge is an explosive material made by terrorists. These materials can be diverse, be of different efficiencies, but provide a relatively good cover for their maker because they are difficult or even impossible to trace back.

In our opinion, the most dangerous variants are munitions that contain nuclear, biological, or chemical (hereinafter: NBC) components. In the present study I do not examine these explosive devices because the main destruction in such structures is not caused by the explosion (that is not by the explosive material) but by the resulting radiators, infectious agents, or toxic compounds, and the explosion itself is not chemical in nature. Deactivating and handling these devices is the task of a socalled NBC UXO-expert, which is a combination of NBC-defence and UXO missions (Berek, 2016).

\section{Use of Homemade Explosive Materials}

Now we will analyse what homemade explosive devices can be produced with the use of improvised explosive materials, which present a particularly significant problem when used as a tool for asymmetric warfare, both in areas of operation and against civilians in the rear areas.

In this paper, we think for obvious reasons, we do not wish to share recipes, regardless of the fact that downloadable literature can be found on the World Wide Web after a few minutes of searching. 
The plethora of available chemicals, which can be the basis of an explosive material, requires the assassin to acquire the technology of producing them through some specific description and demonstration video. At least if they are not professional chemists. Therefore, there are many options in the hands of terrorists if they want to get explosives in this way.

The presence of two components is necessary for an assassin to produce an explosive mixture. A mixture of oxidizing agent and fuel or combustible material is required for a satisfactory end result. However, there are special ingredients, mixtures of two or three of which also have explosive properties. In some cases, different bonding agents are also needed to combine the components and to improve the consistency and sensitivity of the mixture. In addition, improvised explosive devices even require some kind of trigger mechanism. However, this is not necessarily sufficient for a successful bomb attack.

The difficult element in this criminal activity - which is beneficial for our safety - lies in the production of the ignition chain. Several variants of an ignition chain can be designed (Lukács, 2017), and those who are familiar with blasting know exactly what the possible elements are. The ignition process is of great importance because explosive materials need an impulse of sufficient energy for detonation. Such an impulse varies by type. For certain initiating explosives a mechanical impulse (e.g., an impact) is sufficient, for example, in the case of primer cap. At the same time, there are other types that do not receive sufficient energy to maintain the chain reaction during their chemical transformation even if an igniter explodes.

If a terrorist produces a material sensitive to mechanical impacts or flame (e.g. lead azide) it may prove a selfdestructive move since such materials are typically used only in few-gram primer caps or fuses. Handling them in large quantities is expressly dangerous.

If more stable and safer explosive material (e.g., an ammonium nitrate-based explosive) is made, then the problem arises that you need a standard industrial or military detonator to initiate the explosion. In many cases, even this is not enough. Some types are not detonator-sensitive, therefore the detonator impulse must be amplified by a fuse for the compound to explode in full volume. Of course, these elements can also be improvised, but the more different types of explosives are made (up to three completely different ones may be needed), the greater the risk and the more "expertise" is required.

Consequently, the manufacturing process of improvised explosive devices made with home-mixed explosives includes the following life-threatening steps:

- manufacturing of explosives;

- filling the explosive into the device, or container of the means of delivery;

- completing the assembly of the explosive device;

- transportation of the explosive device;

- installation and camouflage of the explosive device.

Of course, in some cases these steps may be interchangeable or even omitted, in dependence on the specific type of device. This knowledge is very much needed by professionals who work to identify terrorists and prevent attacks and bombings. Accidents of different extents may occur at the locations of the stages, and the precautionary means and methods can also indicate a criminal activity. 


\section{Identification of Homemade Explosive Materials}

Explosive materials must be accurately identified during site investigations. Weapon intelligence Teams (WIT) operating in areas of operations can play a major role in this, but are also essential in the rear area for investigation activities. In the present paper, we deal with identification procedures that can be applied in the course of military missions.

Identification can provide a lot of help for teams operating in the area of operations. If a terrorist "bomb factory" is inspected by the experts and a homemade explosive material can be identified from some remnants (e.g., a mixing bowl), it can provide immediate assistance to UXO teams operating in the area. In such sites, emphasis should be placed not only on residual materials but also on other materials and equipment found. These materials often appear to be completely ordinary (e.g., nail polish remover, aluminium powder, antifreeze, car battery, certain sweeteners, small diameter rubber tubes, tanks, etc.), but on the basis of their presence well-trained professionals are able to deduce the possible types of explosive materials produced. Of course, the latter method gives a greater variance of the compounds, but it is also an important way of narrowing the variations.

These identification processes are also of great importance at the scene of an attack. In such cases, destruction can no longer be avoided, however, the results of the investigation may be used for preventing further events of similar nature. Even in such events, there is some chemical residue that is characteristic for the actual explosive material, moreover, identifiable pieces may remain from the device. The latter is presumably more likely to occur if the explosive used is not manufactured under industrial conditions and its efficiency differs from standard industrial grade.

These explosives identification tasks require a tool that:

- is able to perform on-site analysis;

- is relatively small in size and weight;

- is appropriate for military use dust-, drop-, and impact-resistant;

- is easy to maintain before and after use, does not require complicated installation;

- does not or just rarely requires expensive central maintenance;

- is able to display the data, which can be saved and transferred to other devices.

Chemical analysers manufactured by Thermo Fisher Scientific are capable of meeting the described requirements. Identification is basically done by the devices with the use of two methods. The First Defender RMX Handheld Chemical Analyser uses Raman spectroscopic method. The design of the device allows for analysing the materials without taking samples, at the specific site, without moving anything. These materials may be solid or liquid, but the transparency of the storage bottle or vial affects the result. Among the materials tested, the device is capable of identifying explosives, narcotics, toxic industrial chemicals, chemical warfare agents, and various special components. Optionally, it can be carried by robots, requiring minimal resources for maintenance. 


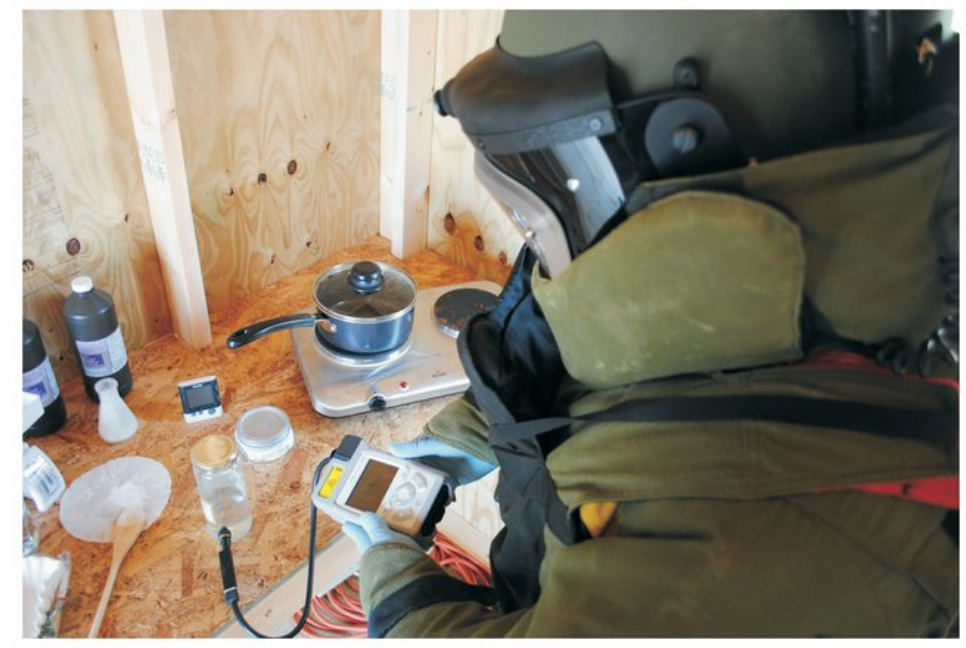

Figure no. 2: First Defender RMX in use

(Source: FirstDefender ${ }^{\mathrm{TM}}$ RMX Handheld Chemical Identification)

The other device is the True Defender FTXi Handheld Chemical Analyser. Its operation is based on FTIR spectrometer, its maintenance requires minimum resources. This type requires sampling of the residues found. Samples can be either volatile liquids, residues of solid granules, or even pills. This analyser is also capable of identifying the above types of chemicals, with the exception of possible charges of chemical weapons. The great advantage is that it is capable of sending the results immediately to the indicated recipients via text message or email, thanks to the built-in mobile phone technology (Handheld FTIR for Chemical and Explosive Identification, 2020).

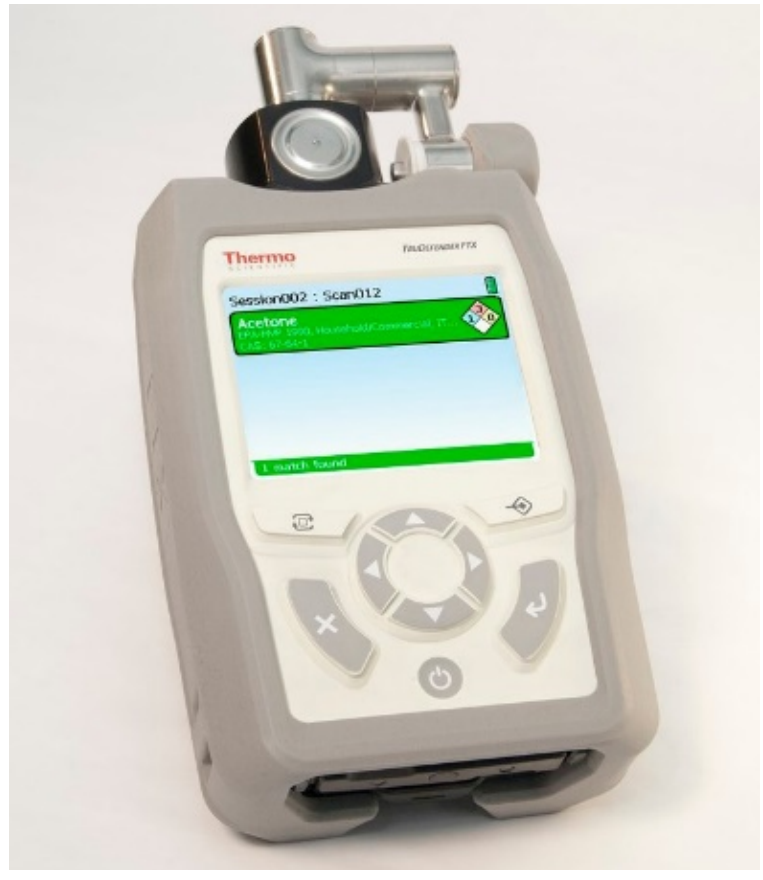

Figure no. 3: First Defender FTX / FTXi

(Source: TruDefender ${ }^{\mathrm{TM}}$ FTX/FTXi Handheld FTIR for Chemical Identification, 2020) 
The two devices can be used separately, but for the purposes of the present study, their use in pair is relevant. These devices, when operated in a complementary mode, are capable of covering a particularly wide range of identification. Their capabilities are adequate for military use, while their "weaknesses" inherent in their operating systems can be eliminated through parallel use for testing.

\section{Conclusions}

The dangers posed by the use of homemade explosives are therefore significant. These materials have the potential to provide an alternative for military and industrial explosive materials in criminal explosions. Although they are mostly of poorer quality yet effective reproductions.

The technical devices described in this paper are capable of efficiently performing the identification of various chemicals, including both homemade explosives and related precursors. In addition, they comply with the conditions set up on a professional basis, which we have generally determined for analysers based on our experience and results.

The combined use of the two analysers can make a significant contribution to increasing the level of security in operational areas, as the full, broader identification of homemade explosive materials is an important element in the fight against terrorism.

\section{REFERENCES}

Berek, T. (2016). An NBC (CBRN) UXO Team as a Response to Security Challenges. Bolyai Szemle, Vol. 25, Issue 4, 22-34.

Bucsák, M., et al. (2015). 70 Years in the Shadow of Risk to Life - the History of Hungarian EOD Units 1945-2015. Zrínyi Kiadó, Budapest, 29.

Daruka, N. (2012). Characteristics of the Use and Deactivation of Criminal Explosive Devices. Military Technical Bulletin, Vol. 22. Special Edition, 26-34.

Horváth, T. (2019). Emergency cases at countering improvised explosive devices, and their potential management. Land Forces Academy Review, Vol. 94, Issues 2, 95-106.

Kovács, Z. (2012). Main Types of Improvised Explosive Devices. Military Technical Bulletin, Vol. 22, Issue 2, 37-52.

Lukács, L. (2017). Chapters from the Development of Hungarian Explosion Technology with Special Regard to Potential Trends of Further Development and New Challenges. Budapest: Dialóg Campus.

Resperger, I. (2018). Terrorist Organisations, Methods, Procedures. Szakmai Szemle, Vol. 16, Issue 2, 5-30.

Vass, Gy., \& Padányi, J. (2016) Some Informal Money Transfer Systems of Funding International Terrorism. Military Science, Vol. 9, Issue 1, 212-223.

FirstDefender ${ }^{\mathrm{TM}} \quad R M X$ Handheld Chemical Identification, available at: https://www.thermofisher.com/order/catalog/product/FIRSTDEFENDERRMX\#/FIRSTDEFE NDERRMX, accessed on 24 April 2020.

Handheld FTIR for Chemical and Explosive Identification, available at: https://www.thermofisher.com/document-connect/document-connect.html?url=https $\% 3 \mathrm{~A} \% 2$ F\%2Fassets.thermofisher.com\%2FTFS-Assets\%2FCAD\%2Fbrochures\%2Ftrudefenderbrochure.pdf\&title=QnJvY2h1cmU6IFRydUR1ZmVuZGVyIEhhbmRoZWxkIEZUSVIgZm9 yIENoZW1pY2FsIElkZW50aWZpY2F0aW9u, accessed on 24 April 2020.

TruDefenderTM FTX/FTXi Handheld FTIR for Chemical Identification, available at: https://www.thermofisher.com/order/catalog/product/TRUDEFENDERFTXI?SID $=$ srch-srpTRUDEFENDERFTXI\#/TRUDEFENDERFTXI?SID=srch-srp-TRUDEFENDERFTXI, accessed on 24 April 2020. 